\title{
FIGURINO DE DANÇA: RELAÇÃO EXISTENTE ENTRE CORPO E VESTIMENTA
}

\author{
Karoline Mohr ${ }^{1}$ \\ karolinem@furb.br \\ Gabriela Sborz² \\ gsborz@furb.br
}

\section{RESUMO}

O presente artigo, intitulado como FIGURINO DE DANÇA: RELAÇÃO EXISTENTE ENTRE CORPO E VESTIMENTA, visa ressaltar a importância que possui o Figurino de Dança. Especificando também qual a relação que se estabelece entre as áreas de Dança e Moda, mostrando a influência que uma área possui sobre a outra no momento de confecção das vestimentas. A metodologia utilizada para a construção desta escrita é a de pesquisa bibliográfica, contando com referencial teórico encontrado em livros e também pesquisas acadêmicas que abordam ambas as áreas trazidas como o cerne desta escrita. A partir do momento em que o bailarino se insere no mundo (cênico) da Dança, inicia-se a familiarização e a relação entre corpo-figurino, que com o decorrer do tempo se mostra influente e protagonista em conjunto com elementos como coreografia, cenografia, iluminação, sonoplastia e com forte influência sobre a movimentação e rendimento corporal do bailarino, que são diretamente influenciados pela maneira da qual o figurinista constrói o figurino.

Palavras-chave: Figurino de Dança. Corpo. Dança. Moda.

\section{ABSTRACT}

The present article, entitled as DANCE COSTUME: RELATIONSHIP BETWEEN BODY AND DRESS, seems to stand out the matter that have the Dance Costume. Specifying as well wich relationship that sattle down between the area of Dance and Fashion, showing the influence that one has above the other in the moment of the clothes confeccion. The methodology that was used for the construction of this writing is the bibliographic research, relying on theoretical framework found on books and also academic researches that address both areas brought up as the heart of this writing. From the moment that the dancer inserts himself in the (cenic) world of the Dance it begins the familiarization and the relationship between body-dance costume wich over time proves to be influential and protagonist together with elements like choreography, cenography, ilumination, sound design and a big influence above the movement and the dancer's body performance that are directly influenced by the way that the figurinist makes the costume.

Key words: Dance Costume. Body. Dance. Fashion.

\footnotetext{
${ }^{1}$ Acadêmica da $7^{\text {a }}$ fase da Licenciatura em Dança da FURB. Bailarina do Grupo de Danças Alemãs da FURB. Futura professora, pesquisadora e artista na área da Dança e também dos Figurinos de Dança.

2 Docente do curso de Bacharel em Design de Moda da FURB.
} 


\section{INTRODUÇÃO}

O Figurino de Dança, objeto principal deste artigo, é um elemento que necessita de maior atenção e pesquisa, devido ao fato do seu protagonismo dentro de trabalhos coreográficos, cada vez mais evidente. Um dos objetivos, para construir esta escrita, é manifestar olhares mais pessoais de um corpo dançante (autora) sobre os figurinos já utilizados em cena. Outro objetivo que podemos acrescentar é ressaltar a importância da relação que se estabelece entre a Dança e a Moda no momento de criação e confecção do Figurino de Dança. Sendo assim, abrimos aqui um campo interacional entre duas áreas que se parecem tão distintas, mas que se conversam diretamente quando o assunto é o Figurino de Dança.

No entanto, a pesquisa sobre este tema ainda é muito escassa e, consequentemente prematura. Desta forma, a metodologia de pesquisa utilizada para a construção deste artigo, é pautada em pesquisa bibliográfica, construída por referencial teórico primário (livros) e complementado com material secundário (pesquisas acadêmicas), o que reforça ainda mais a necessidade de pesquisa sobre algo tão importante como o Figurino de Dança.

A divisão desta escrita está pautada em um momento de reflexões pessoais que interagem com escritas de autores que pesquisam sobre figurinos e que interatuam com as áreas de Dança e Moda. Neste primeiro momento, são trazidas memórias pessoais da autora, que servem como elementos reflexivos acerca dos figurinos construídos e utilizados em um projeto social. No segundo momento, são abordados pontos importantes dos processos da Moda na construção dos Figurinos de Dança e, como estes processos influenciam tanto na vestimenta quanto nos corpos dançantes. Por fim, são apresentadas as conclusões finais/resultados obtidos através das pesquisas feitas para a montagem desta escrita.

\section{UM OLHAR DO BAILARINO SOBRE O FIGURINO DE DANÇA E SUA VESTIBILIDADE}

Até aqui, os anos dançados pela autora do presente artigo, somam ao todo 14 anos (2007 2021) compostos de muita pesquisa corporal, estudos, erros, acertos e reformulações de pensamentos acerca da Dança, incluindo os figurinos utilizados ao longo de sua trajetória. Foram vários figurinos utilizados até o momento, que a fazem refletir sobre seus significados e, de que maneira estes influenciaram nos resultados de movimentação corporal obtidos enquanto presente no palco. 
Segundo Cravo (2008), o figurino, ao vestir o bailarino, torna-se segunda pele, ou seja, vira parte do corpo daquele que o veste. Desta forma, cada vez que este corpo veste um figurino, uma nova forma de se movimentar surge, fazendo com que a relação entre corpo-figurino traga novas ressignificações, a partir da criação de novas perspectivas em relação a coreografia e também influenciando nas maneiras de improviso na construção de um novo personagem. "O figurino passa a incorporar novas maneiras de criar para o performer" (CRAVO, 2008, p. 154 - 155).

É a partir destas e outras falas que usaremos no decorrer deste artigo, que podemos começar a refletir sobre a relação entre corpo-figurino, que construímos no decorrer de nossa trajetória dentro da Dança. Em 2007, a autora, Karoline Mohr, dá início a sua vida na Dança. Dentro de um projeto social, oferecido pela prefeitura da cidade onde reside, dá seus primeiros passos e desde então, não consegue se desvencilhar das amarras e da relação existentes com esta área da Arte, na qual segue até hoje. E é dentro deste projeto que começa a desenvolver também o interesse e o olhar crítico sobre as vestimentas que vestem os corpos dançantes, para além da parte coreográfica presente nos palcos, à medida que:

\begin{abstract}
Aliam-se na coreografia todas as imagens de movimentos criados pelo coreógrafo com a diversidade de corpos e neles a multiplicidade de informações. Criar a unicidade visual passa a ser um exercício em que dialogam todas estas informações, ao lado de estímulos, sensações e percepções. E neste ponto começa uma etapa interativa em que a comunicação se faz entre o coreógrafo, que traz uma série de estímulos próprios a serem compartilhados com bailarinos, e especificamente para este artigo, com aquele que cria a segunda pele que se tornará no palco a expressão visual que envolve corpos em cena coreografada. (JÚNIOR, 2017, p. 67)
\end{abstract}

Por ser um projeto social, os figurinos utilizados pelos alunos, não eram tão bem elaborados, no entanto, eram pensados e produzidos para atender as crianças que os vestiriam, da melhor maneira possível. Em algumas apresentações, muitas vezes o figurino utilizado era todo ou parcialmente improvisado. As combinações de roupas utilizadas, na maioria das vezes, eram compostas por calça/shorts jeans, legging preta, camisetas de cores lisas, e tênis ou sapatilha de dança (geralmente na cor preta, já que utilizávamos nos ensaios/aulas). Além dos figurinos improvisados com as roupas comuns (encontradas nos armários dos alunos), são oferecidos figurinos pelo próprio projeto, através de empréstimos. Desta maneira, a professora que não pudesse juntar dinheiro o suficiente ou que não encontrasse algum profissional da área do vestuário para auxiliar na construção de novos figurinos, poderia utilizar os que estivessem disponiveis para o empréstimo. Neste estoque, encontram-se diversos figurinos, que podem ser adaptados às mais diversas coreografias feitas pelas docentes do projeto. Um dos exemplos utilizado até hoje, é este macacão laranja com verde (possui variação de cores) da figura 1, que aparece na próxima página. Este foi o primeiro figurino vestido pela autora, repleto de sentimentos e memórias. 
Figura 1 - Figurino improvisado: macacão laranja com bolso verde e macacão azul com bolso laranja.

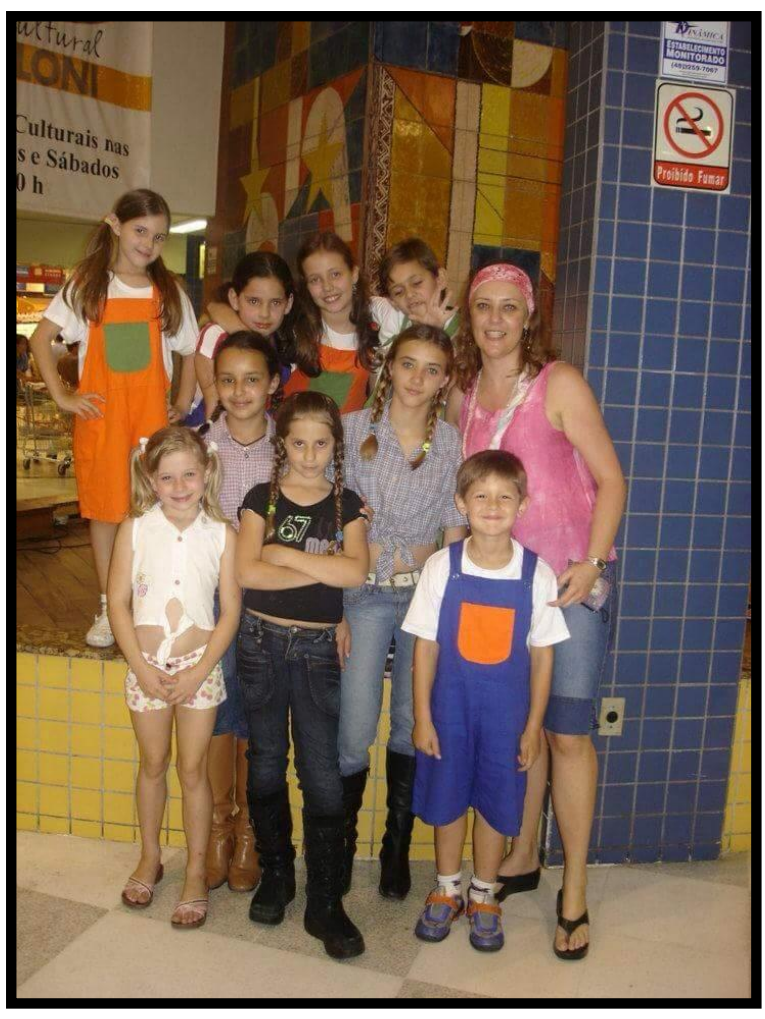

Fonte: Própria.

Apesar deste figurino não ter sido feito especificamente para a coreografia dançada neste dia, estava à disposição para aqueles que precisassem. Alguns outros figurinos improvisados, poderiam ser confeccionados, caso não houvesse para empréstimo, figurinos adequados ao trabalho coreográfico. Sendo assim, "o criador pode apoderar-se desta fonte de informação - a roupa - como referencial simbólico intencional para seu trabalho, bem como pode usá-lo num jogo aleatório de caos e indeterminismo. Esta relação está atrelada ao que ele deseja comunicar através do figurino." (CRAVO, 2008, p. 156)

Na figura 2, na próxima página, as bailarinas estão utilizando um figurino improvisado, que depois é customizado e reutilizado pelas mesmas bailarinas em outra apresentação. Os collants eram das próprias bailarinas, muitos foram doados por ex-alunas, o que explica os diferentes modelos utilizados. Já as calças, foram confeccionadas para serem utilizadas especificamente para esta coreografia, porém, mesmo assim, ocorreram alguns ditos acidentes vestíveis em cena. As calças mais amplas tinham a intenção de ressaltar os movimentos de pernas realizados pelas bailarinas, porém, o excesso de tecido, justamente para influenciar na amplitude de movimento, acabou por atrapalhar e causar alguns 
desconfortos em cena. Escorregões, pisadas nas barras das calças e tropeços foram os mais comuns devido ao tamanho e quantidade de tecido utilizado na confecção das calças. Sendo assim, podemos refletir sobre este figurino e os acidentes vestíveis, quando um figurino é utilizado pela primeira vez, o que nos leva à compreensão de que, quando as relações com o figurino não possuem objetividade no que se deseja, esta falta de clareza transparece na obra. A percepção do criador deve estar atenta a tudo que se relaciona com o figurino, para poder direcionar o foco sem interferências indesejadas. (CRAVO, 2008, p. 156)

Figura 2 - Figurino improvisado: collant preto (vários modelos) e calça branca.

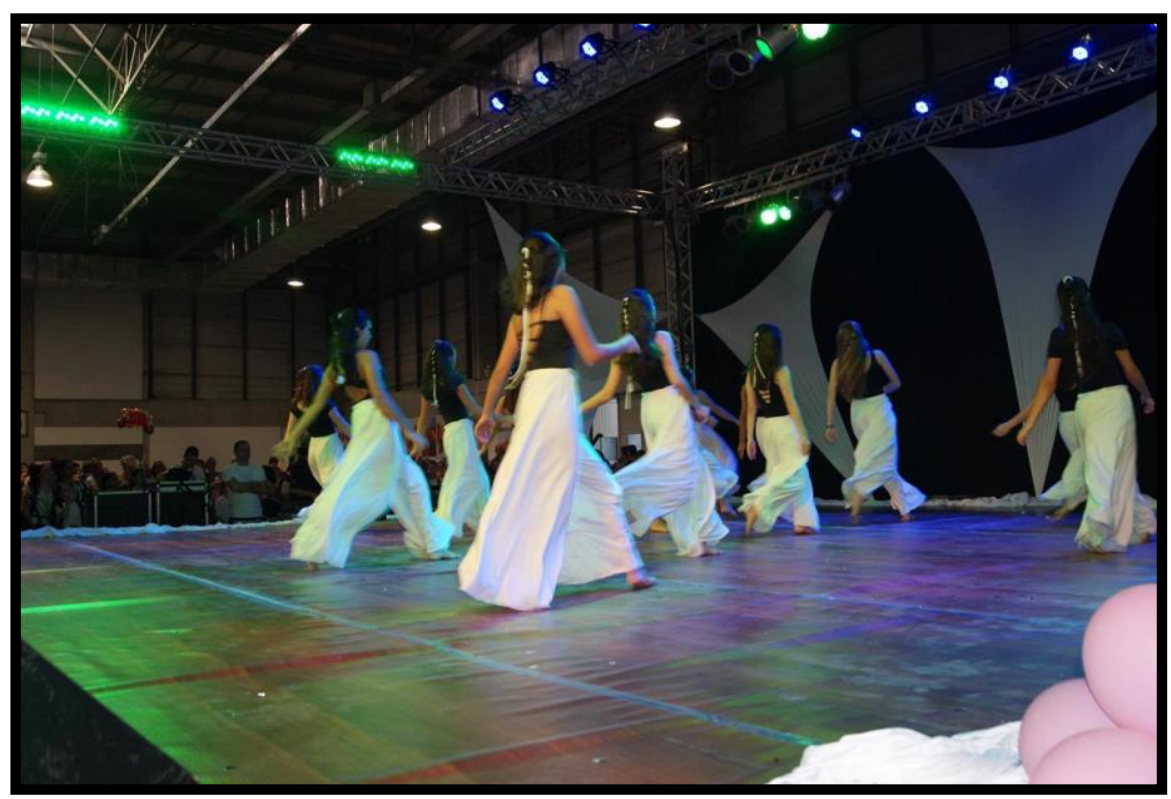

Fonte: Própria.

No momento que estamos em cena, como corpos dançantes, passamos a entender a verdadeira relação que se estabelece entre corpo e figurino e, como essa relação reflete no trabalho coreográfico, assim como na cenografia, iluminação e também na sonoplastia, ou seja, em todo o contexto no qual a cena se insere. A relação entre corpo e figurino que é citada aqui, vai além do simples contexto de uma roupa que veste um corpo. É quando o bailarino que veste um figurino, começa a entender que esta vestimenta, se torna sua segunda pele e passa a ser um elemento que visa comunicar algo a alguém, carregado de significados e também de inúmeras interpretações (desde as mais diretas, ou as mais indiretas, ambas elaboradas de maneira intencional). Esta relação, se constrói e se torna mais visível ao bailarino com o passar do tempo, e não de uma hora para a outra.

Então, quando o performer coloca pela primeira vez um figurino, ele adquire certa impressão da roupa, que no sentido da semiótica pierciana, se constitui numa "primeiraridade", o primeiro contato antes que se produza qualquer tipo de reação. Após este primeiro contato as relações táteis iniciais de troca começam a acontecer e, a partir daí, o performer vai além, criando 
intimidades com as cores, as padronagens, com os modelos, com o cheiro, enfim outros referenciais que a roupa possui. [...] 0 vestir e o despir do performer permite criar uma familiaridade com a roupa e esta se torna sua segunda pele ou a própria pele. Cada vez que ele veste e despe seu figurino passa a ter mais conectividade com o mesmo e com a obra, porque as impressões criadas estão gravadas no figurino, tal qual na sua pele, que abre passagem para entrar e sair daquele mundo que se criou, ou seja, a obra artística. Podemos pensar num ator que, ao vestir seu figurino, acessa mais intimamente o seu personagem e a obra artística; e inversamente, à medida que ele se despe retorna novamente a sua vida cotidiana. Assim o figurino passa a ser um mediador entre corpo e ambiente, entre perfomer e obra artística. (CRAVO, 2008, p. 155)

Além dos figurinos improvisados, utilizávamos também os elaborados e criados de acordo com a temática da coreografia, como por exemplo o que vemos na figura 3, logo em seguida.

Figura 3 - Figurino de mamãe noel, Jantar Natalino.

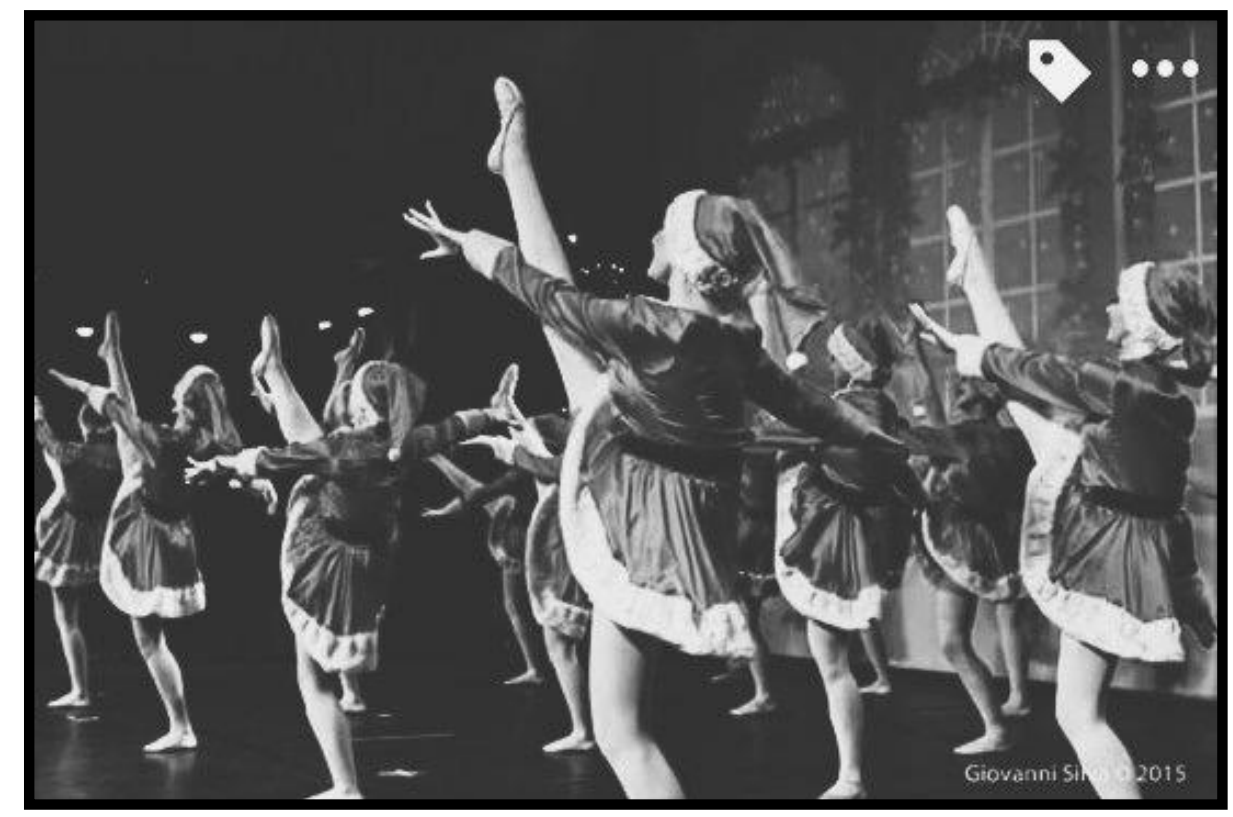

Fonte: Própria. Foto: Giovanni Silva.

Este figurino foi utilizado nas apresentações feitas durante o evento chamado Jantar Natalino. As coreografias eram apresentadas ao público de acordo com a narrativa de uma história natalina, criada pelas professoras/coreógrafas envolvidas no evento. Nesta, podemos interpretar através do figurino, que tratava-se uma coreografia que representava a mamãe Noel, assim como estava sendo contado na história e, assim como na parte narrada sobre os anjos que aparecem na noite de Natal, subíamos ao palco com um figurino que possuía asas - collant, saia, meia calça, sapatilhas e arranjo de cabelo - tudo na cor branca, trazendo uma representação simbólica de um verdadeiro anjo. Aliado a todo o figurino, havia toda a movimentação mais voltada ao Balé Clássico (romântico), pautado em uma movimentação delicada e expressão facial que demonstrasse leveza. 
Dessa maneira, de uma ideia inicial, do coreógrafo, vê-se materializar, se formar ou mesmo deformar, imagens de corpos dançantes que se movimentam, cruzam-se, tocam- se, envolvem-se sobre o palco. Neste processo de materialização soma-se a ideia inicial a uma série de fatores que começam com uma pesquisa capaz de traduzir em vestimenta as referências do coreógrafo, a música, ou sua ausência, que permite unir a observação do movimento com uma dinâmica corporal, a ocupação do espaço registrada em deslocamentos ou posicionamentos estáticos que convergem para uma intenção cênica. (JÚNIOR, 2017, p. $67-68)$

Certamente, em todo e qualquer enredo coreográfico, podemos encontrar erros e acertos na construção dos figurinos, independente da modalidade, profissionalismo no qual o grupo/companhia está inserido e também, da maneira na qual o figurino é construído para vestir os corpos que dançam, entendendo que, certamente, para construirmos uma boa vestimenta para o corpo que dança, precisamos nos atentar a alguns detalhes que, do início ao o fim, desde a criação, até o produto final, fazem total diferença.

\section{O PAPEL DA MODA EM RELAÇÃO A CONSTRUÇÃO DO FIGURINO DE DANÇA E COMO ELA INFLUENCIA PARA O RENDIMENTO DO BAILARINO EM CENA}

O Figurino de Dança é o elemento que necessita maior interação possível entre as áreas de Dança e Moda, tendo em vista a necessidade de um figurino integrado com a obra coreográfica e com o público, sobretudo, vestindo bem o corpo do bailarino e contribuindo, de maneira positiva em sua movimentação e estética. A partir do momento em que o figurinista (ou profissional da área do vestuário) inicia este trabalho de criação, segundo Iglecio e Italiano (2012), ocorre também o nascimento de uma vestimenta que visa comunicar algo a alguém, ou seja, surge um figurino que passa a ser um objeto comunicador.

Para que o figurino criado seja pautado em todas as características necessárias, Iglecio e Italiano (2012) trazem um ponto muito importante em sua escrita, que é a pesquisa inicial. A pesquisa inicial nada mais é do que uma conversa entre figurinista e o responsável pelo trabalho coreográfico, podendo envolver os bailarinos, ou seja, os corpos que serão vestidos. Após a conversa inicial entre profissional do vestuário e profissional(ais) da dança, tem início uma série de pesquisas externas. Nestas pesquisas externas, o figurinista busca referências que não estão necessariamente dentro da área da dança, mas sim, de contexto histórico (ano, década, século, milênio) em que o trabalho coreográfico se passa, 0 contexto social no qual está inserido (país, estado, cidade, região, continente, cultura). Desta forma, o figurinista não se atenta apenas aos detalhes passados pelo responsável do trabalho coreográfico, podendo inserir influências que pertençam também ao mundo da moda e externo ao da dança. 
(...) a criatividade, a escolha dos materiais e o uso de processos adequados, irão sofrer alterações no percurso do processo de criação. Parte - se de referências visuais e bagagem cultural, mas acrescenta-se o uso de novas tecnologias. Nesse processo, a importância está não apenas no criar, mas no transmitir o que se pretende, fazendo com que o público perceba, ainda que de forma intuitiva, a mensagem ou os signos que estão representados no figurino (IGLECIO e ITALIANO, 2012, p. 5).

A partir destas pesquisas externas de contextualização (geral e específica), surgem então as pesquisas que envolvem os corpos dos bailarinos. Pesquisas estas, tão necessárias quanto as outras, devido ao fato de que se o figurino não estiver de acordo com os corpos (ou corpo no caso de uma coreografia solo), afeta diretamente o rendimento e a estética necessária que deve estar presente na vestimenta de um corpo dançante. Para melhor entender e interpretar a importância do estudo corporal no momento de confecção da vestimenta, podemos entender que,

0 corpo é o cabide tridimensional que dá não somente vida, mas também alma às roupas. Muitas vezes, a roupa quando vista pendurada em uma arara não agrada, mas quando vestida no corpo torna-se ideal, estabelecendo e mantendo uma cumplicidade que permanecerá viva enquanto estiver em uso (GRAVE, 2010, p. 65).

Os autores Puls, Rosa, Schulte e Toledo (2010), trazem a ergonomia como uma aliada na construção de roupas, adaptada assim para figurinos de dança, tendo em vista que a ergonomia possui como função principal, encaixar o ser humano (corpo) ao ambiente no qual se insere, assim como outros produtos que ocupam os mesmo espaços que o corpo. Já para Grave, "a ergonomia é um conjunto de ciências que visa ao bem-estar e ao conforto do homem" (2010, p. 59), para uma exemplificação mais simples e direta.

Partindo deste estudo ergonômico, que também envolve estudos antropométricos, inicia-se o estudo de modelagem e o início das construções dos modelos, sejam eles utilizando a modelagem plana ou modelagem tridimensional/moulage. A modelagem plana (figura 4, na próxima página), consiste em desenhar as peças do figurino (parte por parte) sobre um papel ou em um programa de computador. Estes desenhos são feitos seguindo o modelo das peças desejadas e com as medidas específicas dos bailarinos. Após a finalização dos desenhos no papel, desenvolve-se um protótipo, geralmente em tecidos mais simples, para que, se necessário sejam realizados os ajustes e então, a confecção da peça final com seus adornos e detalhes de decoração. 
Figura 4 - Modelagem plana em papel.

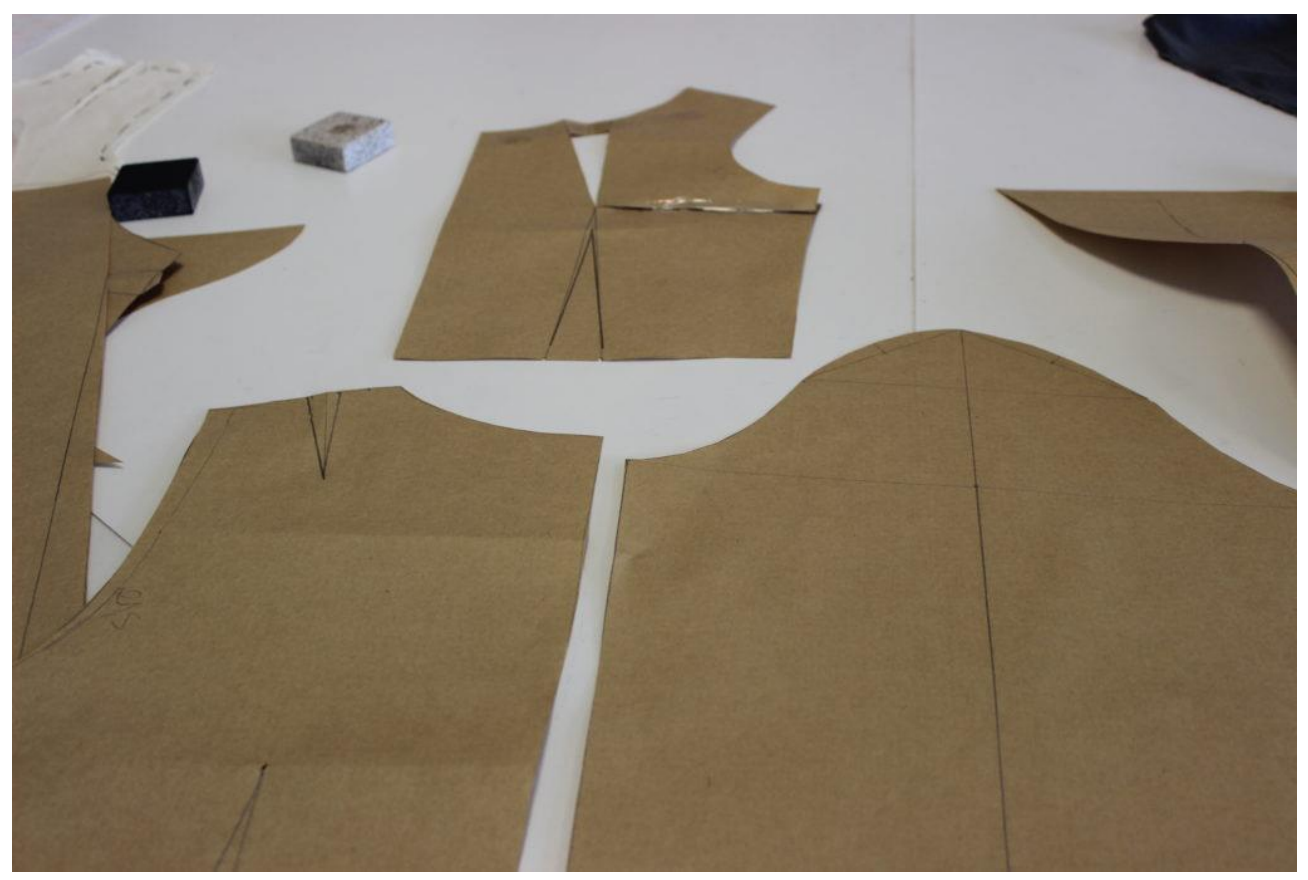

Fonte: Algodão Cru. Disponível em: <https://algodaocru.com.br/modelagem-plana-ou-moulage-qual-e-a-melhortecnica/>. Acesso em: 21 jul. 2021.

A modelagem tridimensional ou moulage, consiste em modelar as peças do figurino em manequins (com medidas iguais ou parecidas com as dos bailarinos) ou nos próprios corpos dançantes. Começa-se pelas marcações principais no manequim/corpo, que são feitas, geralmente com fitas. Depois disto, utiliza-se um tecido para que sejam feitas as marcações de linhas (como pences, recortes, linhas principais como cavas, decote, degolo, linha de cintura, quadril). Depois de todas estas marcações, recorta-se este tecido, alinhava-se (costura simples feita a mão), prova-se a peça no corpo do bailarino e, só então a peça é desenhada no papel para que seja recortada e costurada no tecido final. Aqui, podemos ver a utilização das duas modelagens. Desta forma, pautando-se nos estudos corporais (ergonômicos e antropométricos), esta seria a melhor opção para se apropriar no momento da construção de figurinos de dança, principalmente os que necessitam de mais ajustes e cuidados com detalhes dos corpos dos bailarinos. Parte deste processo pode ser observado na próxima página, na figura 5 . 
Figura 5 - Modelagem tridimensional/moulage, feita em manequim.

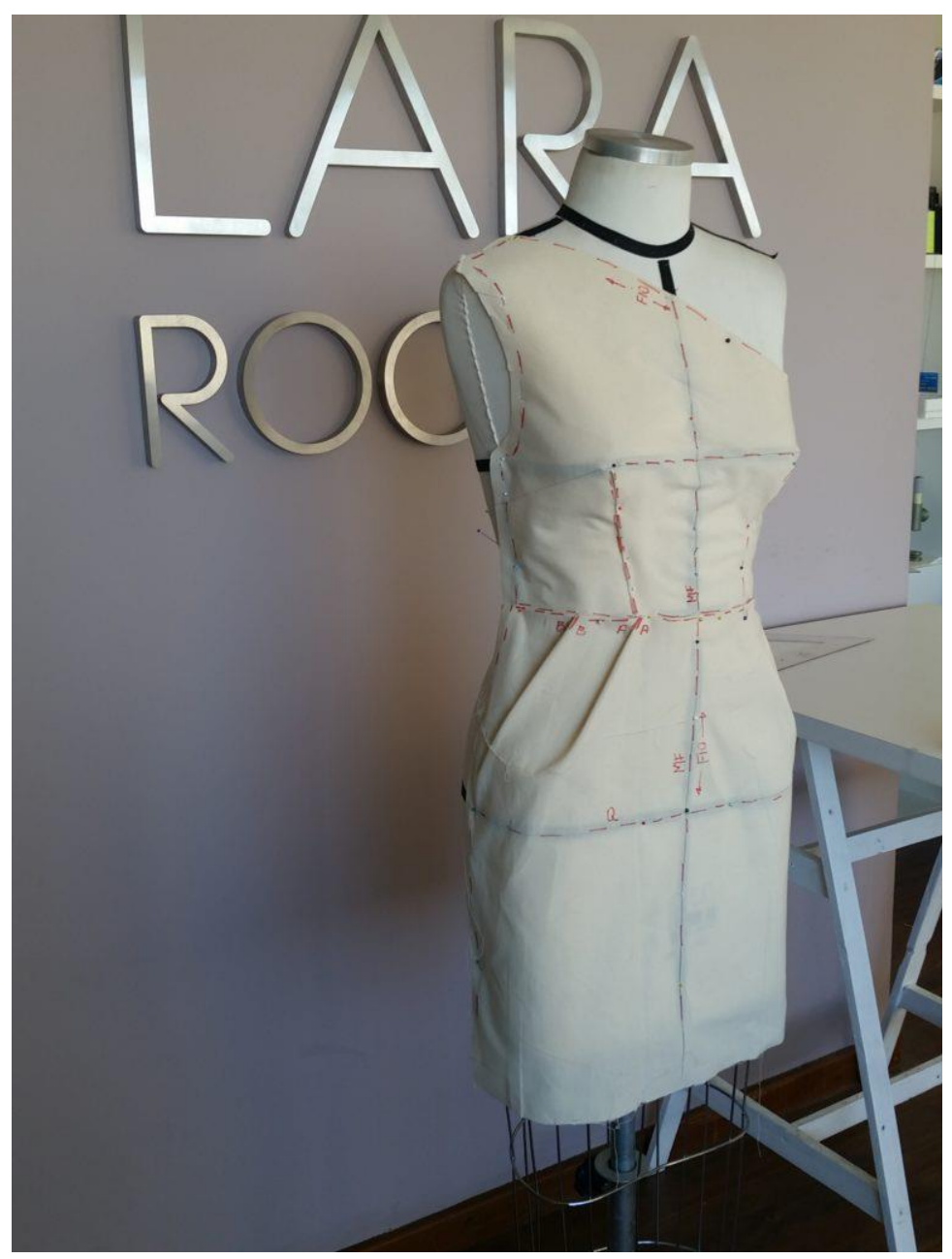

Fonte: Algodão Cru. Disponivel em: <https://algodaocru.com.br/modelagem-plana-ou-moulage-qual-e-a-melhortecnica/>. Acesso em: 21 jul. 2021.

Portanto, através de sucinta apresentação de duas maneiras de realizar a modelagem de peças de vestuário, podemos ter uma noção, mesmo que mínima, de qual se adapta e funciona melhor para construir o Figurino de Dança. Segundo Souza e Mendes (2015), torna-se de certa maneira, inviável se apropriar de estudos e métodos, inclusive de estudo antropométrico, estáticos, pois a todo momento quando falamos em criação e confecção de Figurinos de Dança, estamos falando de peças que irão vestir corpos que se movem, das mais diferentes formas possiveis, sendo assim, podemos passar a refletir sobre os métodos de pesquisa e confecção assumidos pelo figurinista responsável por vestir corpos que dançam. 


\section{CONSIDERAÇÕES FINAIS}

Após as pesquisas e reflexões trazidas aqui durante esta escrita, podemos estabelecer 0 Figurino de Dança como um elemento protagonista inserido em trabalhos coreográficos. Já não cabe mais ao diretor/coreógrafo de uma companhia colocar em cena um corpo vestido por uma roupa qualquer, roupa esta que não estabelece diálogo algum com a cena em geral, corpo do bailarino e principalmente com o público, tendo em vista que neste momento, a vestimenta se torna um objeto comunicador e repleto de significados, estejam eles caracterizados diretamente com a temática do trabalho coreográfico ou indiretamente, fazendo com que novas interpretações possam surgir no decorrer da composição coreográfica ou de acordo com a movimentação corporal/atitude do bailarino que o veste.

De fato, o Figurino de Dança precisa de uma maior atenção dentro do campo de pesquisa nas áreas de Dança e Moda, tendo em vista que neste momento, ambas se relacionam intensamente para que se obtenha um resultado final que atenda as expectativas de todos os envolvidos. A construção de um olhar sobre esta temática ocorre gradativamente, a partir do momento em que um corpo é vestido pela primeira vez. Desta forma, aqui refletimos sobre uma área que pede por novas pesquisas, estudos e atenção, para que então se torne cada vez mais comum os olhares com maior cuidado sobre sua construção.

\section{REFERÊNCIAS}

Algodão Cru. Disponível em: <https://algodaocru.com.br/modelagem-plana-ou-moulage-qual-e-amelhor-tecnica/>. Acesso em: 21 jul. 2021. (Figuras 4 e 5).

CRAVO, Mapi. Figurino. A Pele do Performer. In: XAVIER, Jussara; MEYER, Sandra; TORRES, Vera (org.). Coleção Dança Cênica: pesquisas em dança. Joinville: Letradágua, 2008. p. 153-166. Disponivel em: <https://midiatecadedanca.com/pesquisas-em-danca-colecao-danca-cenica-volume-1/>. Acesso em: 19 jul. 2021.

GRAVE, Maria de Fátima. A moda-vestuário e a ergonomia do hemiplégico. São Paulo: Escrituras, 2010. 126 p. il.

IGLECIO, Paula; ITALIANO, Isabel C. Figurinista e o processo de criação de Figurino. Pós-graduação em Têxtil e Moda-USP)(Pós-graduação em Têxtil e Moda-USP), 2012. Disponível em:

$<$ http://www.coloquiomoda.com.br/anais/Coloquio\%20de\%20Moda\%20-

$\% 202012 /$ GTO9/COMUNICACAO-

ORAL/103760_O_figurinista_e_o_processo_de_criacao_de_figurino.pdf>. Acesso em: 19 jul. 2021. 
LIMA JÚNIOR, Geraldo Coelho. A pele além da pele: diálogos entre tecidos, corpos e mentes dançantes. In: INSTITUTO FESTIVAL DE DANÇA DE JOINVILLE (Joinville) (org.). Dança não é (só) coreografia. 10. ed. Joinville: Instituto Festival de Dança de Joinville, 2017. p. 62-71. Disponível em: <https://midiatecadedanca.com/danca-nao-e-so-coreografia/>. Acesso em: 21 jul. 2021.

PULS, Lourdes Maria. ROSA, Lucas da. SCHULTE, Neide Köhler. TOLEDO, Daiane. Figurino para Dança: A Relação da Roupa com a Coreografia. In: Colóquio de Moda, 6., 2010, São Paulo. Anais eletrônicos. p. 01 - 10. Disponível em:

<http://www.coloquiomoda.com.br/anais/Coloquio\%20de\%20Moda\%20\%202010/68824_Figurino_para_danca_-_a_relacao_da_roupa_com_a_coreogr.pdf>. Acesso em: 21 jul. 2021.

SOUZA, Pétala Tainá de Oliveira de; MENDES, Francisca Dantas. O CORPO DANÇANTE COMO SUPORTE PARA O FIGURINO DE DANÇA. In: ENCONTRO NACIONAL DE PESQUISA EM MODA, 5., 2015, Novo Hamburgo. Anais. Novo Hamburgo: -, 2015. p. 1-13. Disponível em: $<$ http://www.feevale.br/Comum/midias/a0f75834-20bf-4549-b9afc0dc78596375/0\%20CORPO\%20DAN\%C3\%87ANTE\%20COMO\%20SUPORTE\%20PARA $\% 200 \% 20$ FIGURINO\%20DE\%20DAN\%C3\%87A.pdf>. Acesso em: 21 jul. 2021. 